\title{
Role of betulinic acid derivative SH-479 in triple negative breast cancer and bone microenvironment
}

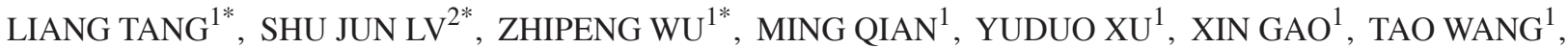

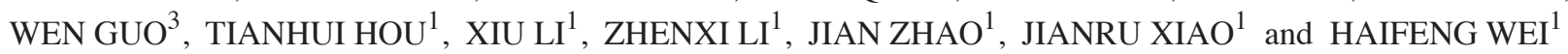 \\ ${ }^{1}$ Spine Tumor Center, Department of Orthopedic Oncology, Changzheng Hospital, Second Military Medical University, \\ Shanghai 200003; ${ }^{2}$ Department of Orthopedics, Hai'an People's Hospital, Jiangsu, Hai'an 226600; \\ ${ }^{3}$ Department of Orthopedics, Taizhou People's Hospital, Jiangsu, Taizhou 225300, P.R. China
}

Received September 3, 2020; Accepted April 8, 2021

DOI: $10.3892 / \mathrm{ol} .2021 .12866$

\begin{abstract}
Breast cancer has a high prevalence in the general population and is often associated with bone metastasis. Specific therapeutic targets are missing for triple negative breast cancer (TNBC), which presents some immunogenic characteristics. Betulinic acid (BA) has been reported to have some anti-tumor properties, and its modified derivative SH-479 was demonstrated to inhibit TNBC bone metastasis. The present study aimed to investigate the effect of the BA derivative $\mathrm{SH}-479$ on breast cancer and bone microenvironment. The effect of BA and its derivative SH-479 on MDA-MB-231 cell proliferation was determined with the MTS method. The cytotoxicity effect of SH-479 was evaluated using the Live and Dead assay. Cell microfilament changes were observed by F-actin staining. The effects of $\mathrm{SH}-479$ on PARP protein expression and cell cycle were detected by western blotting and flow cytometry, respectively. The migratory ability of breast cancer cells treated with $\mathrm{SH}-479$ was determined by migration assay. The effect of SH-479 on osteoclast differentiation induced by breast cancer cells was observed using the osteoclast differentiation assay and tartrate-resistant acid phosphatase staining. The effects of SH-479 on T lymphocytes and bone marrow-derived suppressor cells (MDSCs) in bone marrow from mice were observed by flow cytometry. The results demonstrated that $\mathrm{SH}-479$ significantly inhibited the proliferation of the TNBC cell line MDA-MB-231 at lower concentrations but had no significant effect on normal cells and other types of breast cancer cells for the same concentration.
\end{abstract}

Correspondence to: Professor Jianru Xiao or Professor Haifeng Wei, Spine Tumor Center, Department of Orthopedic Oncology, Changzheng Hospital, Second Military Medical University, 415 Fengyang Road, Shanghai 200003, P.R. China

E-mail: xiaojianrumail@yeah.net

E-mail: weihaifengmai@yeah.net

${ }^{*}$ Contributed equally

Key words: betulinic acid derivative, breast cancer, bone metastasis
Furthermore, SH-479 significantly interfered with actin microfilaments in breast cancer cells but had no effect on cell apoptosis and cell cycle. In addition, SH-479 inhibited the migratory ability of breast cancer cells and the differentiation of osteoclasts induced by breast cancer cells. In bone marrow immune microenvironment, addition of SH-479 could promote the proliferation of CD4+T lymphocytes and inhibit the proliferation of MDSCs. Taken together, the findings from this study demonstrated that $\mathrm{SH}-479$ inhibited the activity and migratory ability of TNBC cells and the differentiation of osteoclasts induced by TNBC and affected the bone marrow immune microenvironment. SH-479 may therefore inhibit breast cancer metastasis to bones, indicating that SH-479 may be considered as a promising drug to inhibit bone metastasis in patients with breast cancer.

\section{Introduction}

Breast cancer is the most common female malignant tumor worldwide (1). Breast cancer can be divided into different subtypes according to cancer cell morphology and cell surface receptors, including Luminal type, human epidermal growth factor receptor 2 (HER2) type and triple negative breast cancer (2). Bone tissue is the most common site of breast cancer metastasis (3). Depending on the stages of breast cancer, the incidence of bone metastasis can reach $75 \%$ (4-6). Even early breast cancer has a $22 \%$ incidence of bone metastasis, and bone metastases occurs after $\sim 8.4$ years $(7)$. The average overall survival rate for patients with breast cancer and bone metastasis is only 40 months (6).

Triple negative breast cancer (TNBC) is a specific subtype of breast cancer, which is characterized by a negative expression of estrogen receptor (ER), progesterone receptor (PR) and HER2 receptor $(8,9)$. TNBC is more common in premenopausal women, and the age of onset is earlier than other types of breast cancer (10). TNBC is an independent clinicopathological type with strong invasiveness and poor prognosis. TNBC accounts for $10-20 \%$ of all breast cancers $(11,12)$. Although this subtype of breast cancer is sensitive to chemotherapy (13), the clinical outcome and prognosis remain poor following standard treatment. Because patients with TNBC have negative expression for ER, PR 
and HER2, they cannot benefit from endocrine therapy and targeted therapy against HER2. Immunotherapy, which is a new method to treat tumors, has been gradually applied to the treatment of TNBC. For example, suppression against immune checkpoint PD-L1 can be used as a therapeutic approach (14). At present, TNBC has become a new hotspot of breast cancer research in the world.

Numerous active principles from Chinese herbal medicines have been found to have anti-cancer effects, and some have been approved by the Food and Drug Administration (15). For example, betulinic acid (BA) has been widely studied because of its safety and effect on numerous biological functions. Previous studies have demonstrated that BA has some therapeutic effects, including anti-inflammation $(16,17)$ and treatment of diabetes by selective activation of Tgr5 receptors $(18,19)$. BA and its derivative compounds show antiplasmodial activity against chloroquine-resistant Plasmodium falciparum parasites (20). BA also has a certain therapeutic effect on tumors, and it was reported that it can promote the apoptosis and regulate the cell cycle of glioma cancer cells $(21,22)$.

Because of the poor solubility and the low bioavailability of BA, 35 BA derivatives were obtained and the compound 20 (SH-479) inhibitory effects of RANKL-induced osteoclastogenesis of these derivatives was evaluated in TNBCs. Compound 20 has been reported to exhibit a dramatic increase in inhibitory potency compared with BA (23). In order to maintain BA activity, the water solubility of the derivatives was enhanced and the bioavailability of the derivatives was subsequently improved.

The activity and migratory ability of tumor cells can directly affect the occurrence of distant metastasis. Tumor cells are compared to the "seeds" of plants. Only when they reach the proper "soil", which is the organs with metastatic lesions, can the seeds grow, and metastasis occurs (24). Bone marrow microenvironment plays an important role in the development of bone metastasis. Osteoclasts can decompose bone, release increased growth factors and promote the proliferation of tumor cells, ultimately forming a vicious circle (25). Simultaneously, immunosuppressive cells are recruited into the bone marrow microenvironment, such as Treg and bone marrow-derived suppressor cells (MDSCs) (26,27). Immune cells in the bone marrow microenvironment are inhibited when bone metastasis occurs, promoting tumor cell immune escape. Breast cancer, lung cancer and multiple myeloma inhibit CD8+T lymphocytes by recruiting MDSC and thus promote tumor development (28). The present study aimed to investigate the effect of the BA derivative $\mathrm{SH}-479$ on breast cancer and bone microenvironment.

\section{Materials and methods}

Cell culture. The cell lines MDA-MB-231, MCF-7, SKBR3, MCF-10A and RAW264.7 were purchased from the Cell Bank of Type Culture Collection of The Chinese Academy of Sciences. MDA-MB-231, MCF-7 and SKBR3 cells were cultured in Dulbecco's modified Eagle's medium (DMEM; Gibco; Thermo Fisher Scientific, Inc.) supplemented with $10 \%$ FBS (HyClone; Cytiva) and $100 \mathrm{U} / \mathrm{ml}$ penicillin-streptomycin (Gibco; Thermo Fisher
Scientific, Inc.). MCF-10A were cultured in DMEM/F12 medium (Gibco; Thermo Fisher Scientific, Inc.) containing 5\% horse serum (Invitrogen; Thermo Fisher Scientific, Inc.), $10 \mu \mathrm{g} / \mathrm{ml}$ insulin (Invitrogen; Thermo Fisher Scientific, Inc.), $20 \mathrm{ng} / \mathrm{ml}$ epidermal growth factors (Invitrogen; Thermo Fisher Scientific, Inc.), $100 \mathrm{ng} / \mathrm{ml}$ cholera toxin (Sigma-Aldrich; Merck KGaA) and $0.5 \mu \mathrm{g} / \mathrm{ml}$ hydrocortisone (Invitrogen; Thermo Fisher Scientific, Inc.). RAW264.7 were cultured in $\alpha$-minimum essential medium ( $\alpha$-MEM; Gibco; Thermo Fisher Scientific, Inc.) supplemented with $10 \% \mathrm{FBS}$ and $100 \mathrm{U} / \mathrm{ml}$ penicillin-streptomycin. All cells were placed at $37^{\circ} \mathrm{C}$ in a humidified incubator containing $5 \% \mathrm{CO}_{2}$.

Cell viability assay. A total of 35 BA derivatives were obtained and the compound 20 was named SH-479. To obtain $\mathrm{SH}-479$, a solution of BA (2.28 g, $5 \mathrm{mmol})$ in tetrahydrofuran $(10 \mathrm{ml})$ was added dropwise to a stirring solution of 2-iodoxybenzoic acid (2.1 g, $7.5 \mathrm{mmol})$ in DMSO $(30 \mathrm{ml})$ at $23^{\circ} \mathrm{C}$. The reaction mixture was stirred for $2 \mathrm{~h}$ at $23^{\circ} \mathrm{C}$ and then diluted with ethyl acetate (AcOEt; $30 \mathrm{ml}$ ) and washed with brine $(50 \mathrm{ml})$. The organic layer was dried over anhydrous $\mathrm{Na}_{2} \mathrm{SO}_{4}$ and concentrated in vacuo. The residue was purified by flash chromatography (petroleum ether/AcOEt; 8/1 v/v) to give compound $1(2.05 \mathrm{~g}, 90 \%)$ as a white solid (melting point, $\left.251-253^{\circ} \mathrm{C}\right)(23)$. The concentrations used for BA are 0-25 $\mu \mathrm{M}$. The concentrations used for $\mathrm{SH}-479$ are $0-10 \mu \mathrm{M}$. The durations of the treatments was $72 \mathrm{~h}$. The effect of BA and SH-479 on cell viability was determined using the MTS method following the instructions from the Cell Titer 96 Aqueous One Solution Cell Proliferation assay (Promega Corporation). Briefly, the cell density was adjusted to $10^{5} / \mathrm{ml}$. The cell suspension was inoculated into 96 -well plates at $100 \mu \mathrm{l} /$ well and cultured overnight. Cells were treated with BA (0-25 $\mu \mathrm{M})$ and SH479 $(0-10 \mu \mathrm{M})$ and cultured for $72 \mathrm{~h}$. MTS solution $(20 \mu \mathrm{l})$ was added to each well and incubated for $4 \mathrm{~h}$. The absorbance was read at $490 \mathrm{~nm}$ on a VERSA max microplate reader (Molecular Devices, LLC).

Live and dead assay. The cytotoxicity of SH-479 on MDA-MB-231 cells was assessed using Live and Dead assay kit (Invitrogen; Thermo Fisher Scientific, Inc.) as previously described (29). Briefly, 2,500 cells were seeded into 96-well plates. After cell attachment, the cells were treated with SH479 (0-10 $\mu \mathrm{M})$ for $30 \mathrm{~h}$. Cells were stained with Live and Dead reagent $(5 \mu \mathrm{M}$ ethidium homodimer and $5 \mu \mathrm{M}$ calcein-AM) and were incubated at $37^{\circ} \mathrm{C}$ for $45 \mathrm{~min}$. Live and dead cells were observed under a fluorescence microscope (magnification, x20).

F-actin assay. MDA-MB-231 were seeded into 96-well plates (5,000 cells/well) and treated with SH-479 (0-10 $\mu \mathrm{M})$. After 3 days, cells were fixed with $4 \%$ paraformaldehyde for $10 \mathrm{~min}$ at room temperature and subsequently incubated for $5 \mathrm{~min}$ at room temperature with PBS containing 0.1\% Triton-X 100 and with rhodamine conjugated phalloidin (cat. no. R415; 1:200 in PBS; Thermo Fisher Scientific, Inc.) for $30 \mathrm{~min}$ in the dark at room temperature. F-actin staining was observed under an inverted fluorescence microscope (Olympus Corporation; magnification, $\mathrm{x} 40$ ). 
Western blotting. MDA-MB-231 cells were lysed on ice using RIPA buffer (cat. no. R0278; Sigma-Aldrich; Merck KGaA). Protein concentration was evaluated using the BCA method. Proteins $(30 \mu \mathrm{g})$ were separated by $10 \%$ SDS PAGE and transferred onto PVDF membranes. After blocking for $1 \mathrm{~h}$ in $5 \%$ skimmed milk dissolved in PBS, membranes were incubated with primary antibodies against cyclin E (cat. no. SC248 1:500 Santa Cruz Biotechnology, Inc.), PARP (cat. no. AY 0276; 1:1,000; Abways Technology, Inc.), cleaved PARP (cat. no. CY5035; 1:500; Abways Technology, Inc.) and $\beta$-actin (cat. no. A5441; 1:5,000; Sigma-Aldrich; Merck KGaA) at $4^{\circ} \mathrm{C}$ overnight. The membranes were washed three times with PBST $(0.1 \%$ Tween) and incubated with infrared dye-labeled secondary antibody (LI-COR Biosciences) for $1 \mathrm{~h}$ at room temperature. The signal on the membrane was visualized using LI-COR Odyssey System.

Cell-cycle analysis. The effect of SH-479 on cell cycle was determined by flow cytometry. Briefly, cells were serum-starved for $24 \mathrm{~h}$ and treated with $5 \mu \mathrm{M} \mathrm{SH}-479$ for $12 \mathrm{~h}$. Subsequently, cells were fixed in $70 \%$ ethanol at $4^{\circ} \mathrm{C}$ overnight. Cells were stained with propidium iodide (cat. no. R37108; Thermo Fisher Scientific, Inc.) for $30 \mathrm{~min}$ at room temperature. Cell cycle analysis was conducted using a flow cytometry (Becton, Dickinson and Company). The software used for the analysis was FlowJo VX10.0 (FlowJo LLC).

Migration assay. The migration assay was performed in Boyden chambers (Corning Inc.). MDA-MB-231 cells $(80,000)$ were suspended in $100 \mu \mathrm{l}$ DMEM medium and treated with SH-479 (0-5 $\mu \mathrm{M})$. The mixture was added to the upper well of Boyden chambers. DMEM medium (600 $\mu$ l) supplemented with $2 \%$ FBS was added in the lower chamber. After $8 \mathrm{~h}$ incubation, cells that have migrated to the lower chambers were fixed with $4 \%$ paraformaldehyde and stained with $0.1 \%$ crystal violet $5 \mathrm{~min}$ at room temperature. Pictures of the cells were taken under an inverted microscope (Olympus Corporation; magnification, x20) and quantification was performed using Image-Pro 6.0 software (Media Cybernetics, Inc.).

Osteoclast differentiation assay. Since osteoclasts originate from monocytes/macrophages in the bone marrow, monocytes were studied in the present study. A total of $2 \times 10^{3} \mathrm{MDA}-\mathrm{MB}-231$ cells and $5 \times 10^{3}$ RAW264.7 cells were co-cultured in 24-well plate (30). Cells were cultured in $\alpha$-MEM medium containing $10 \%$ FBS and SH-479 (0-5 $\mu \mathrm{M})$. After 7 days, cells were fixed with $4 \%$ paraformaldehyde $5 \mathrm{~min}$ at room temperature and incubated for 5 min with PBS containing 0.1\% Triton-X 100 at room temperature. Cells were subsequently stained with tartrate-resistant acid phosphatase (TRAP) using Leukocyte acid phosphatase kit (Sigma-Aldrich; Merck KGaA) for 5 min at $37^{\circ} \mathrm{C}$. TRAP positive cells were imaged under an inverted microscope (Olympus Corporation; magnification, x40) and counted using Image-Pro software 6.0 (Media Cybernetics, Inc.).

Immunocytometric assay. National Institutes of Health guide for the care and use of Laboratory animals has been followed for these experiments. Animals experiments were approved by the Ethics Committee of East China Normal
University (ECNU; approval no. m20151002). The C57bl/6 wild type male mice ( 8 weeks; $n=3$ ) were purchased from the ECNU, had free access to food pellets and tap water. They were maintained under the standard 12-h dark/light cycle, with controlled temperature $\left(24 \pm 2^{\circ} \mathrm{C}\right)$ and relative humidity (55-60\%). Mice were euthanized by intraperitoneal injection of $3 \%$ pentobarbital sodium $(200 \mathrm{mg} / \mathrm{kg})$ to collect bone marrow. Femurs and tibias were collected from mice and the femoral head and ankle joint were preserved in order to ensure the integrity of the bone marrow cavity. The bone marrow cavities of the femurs and tibias were opened, and the bone marrow was flushed with PBS solution containing 1\% FBS $(31,32)$. The rinsing solution was collected and centrifuged at $125 \mathrm{x} \mathrm{g}$ for $5 \mathrm{~min}$ at $4^{\circ} \mathrm{C}$. After centrifugation, cells collected were resuspended in PBS solution containing $1 \%$ FBS and counted. Cells were then transferred into Eppendorf tube at the concentration of $10^{6} / 100 \mu \mathrm{l}$ for later use and seeded in a $6 \mathrm{~cm}$ plate and cultured in a cell incubator. Cells were treated with $10 \mu \mathrm{M} \mathrm{SH}-479$ for $48 \mathrm{~h}$ at $37^{\circ} \mathrm{C}$ in the $6 \mathrm{~cm}$ plate. After $48 \mathrm{~h}$, one million cells were incubated with $0.5 \mu \mathrm{l}$ antibody (CD3-FITC, cat. no. 100204; CD4-PerCP-Cy5.5, cat. no. 10043; CD8-APC, cat. no. 344722; CD11b-APC, cat. no. 101212; Ly6C-PerCP-Cy5.5, cat. no. 128012; Ly6G-PE, cat. no. 127608; BioLegend, Inc.) at $4^{\circ} \mathrm{C}$ for $30 \mathrm{~min}$. Cells were then washed with $2 \%$ PBS, and T cells and MDSCs (CD11b+) were detected by flow cytometry (Becton, Dickinson and Company). Results were analyzed using FlowJo VX 10.0 software (FlowJo LLC).

Statistical analysis. The data were expressed as the means \pm standard deviation. Differences between two groups were determined using paired Student's t-test. Comparisons between multiple groups were determined by one-way ANOVA followed by Dunnett's post hoc test. All statistical analyses are performed using GraphPad Prism 5.0. (GraphPad Software, Inc.). $\mathrm{P}<0.05$ was considered to indicate a statistically significant difference.

\section{Results}

Inhibitory effect of $\mathrm{BA}$ and $\mathrm{SH}-479$ on the viability of breast cancer cells. The effect of BA (Fig. 1A) and the 35 BA derivatives on TNBC cell viability was assessed. Because only SH-479 showed a significant effect, the results from other BA derivatives were not presented. The results demonstrated that SH-479 (Fig. 1B) significantly inhibited the viability of MDA-MB-231 cells in a concentration-dependent manner after $72 \mathrm{~h}$ compared with the control group (Fig. 1D). However, the viability of MDA-MB-231 cells was significantly inhibited by more than $50 \%$ when higher concentration of BA was added (Fig. 1C).

SH-479 has an inhibitory effect on TNBC cell viability. When using drugs to treat tumors, the common side effects of drugs are toxicity to normal cells. The results showed that only $30 \%$ of MCF-10A viability was inhibited after SH-479 treatment (0.1-10 $\mu \mathrm{M}$; Fig. 2A). Furthermore, SH-479 did not significantly inhibit the viability of the luminal type cell line MCF-7 and Her2 type cell line SKBR3 at low concentration (Fig. 2A). In addition, SH-479 had no effect on the morphology of the 
A

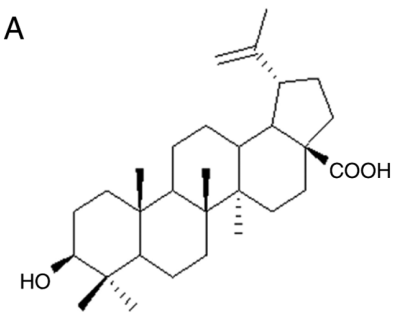

Betulinic acid (BA)

C

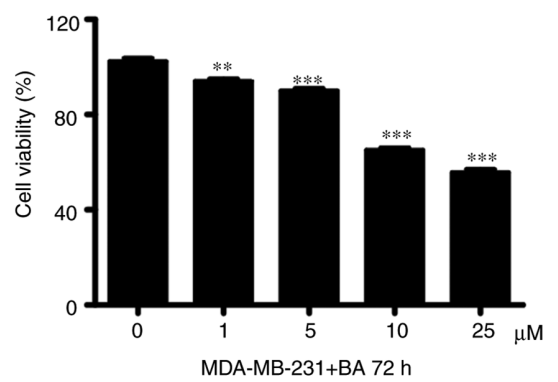

B<smiles>C=C(C)[C@H]1CC[C@]2(C(=O)O)CC[C@]3(C)C(CCC4[C@@]5(C)Cc6c[nH]nc6C(C)(C)C5CC[C@]43C)C12</smiles>

BA derivative

D

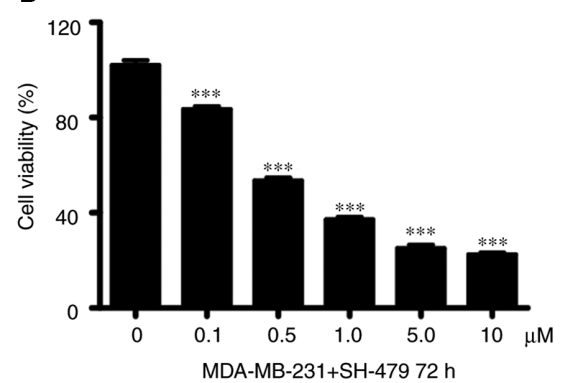

Figure 1. Structure of BA and SH-479 and their effect on breast cancer cells. Human triple negative breast cancer cells MDA-MB-231 were treated with BA and SH-479 for $72 \mathrm{~h}$ with indicated concentrations. (A) Chemical structure of BA. (B) Chemical structure of SH-479. (C) Effect of BA and (D) SH-479 on MDA-MB-231 cell viability determined by MTS assay. Data were presented as the means \pm standard deviation of three individual experiments. ${ }^{* *} \mathrm{P}<0.01$ and ${ }^{* * * *} \mathrm{P}<0.001$. BA, betulinic acid.

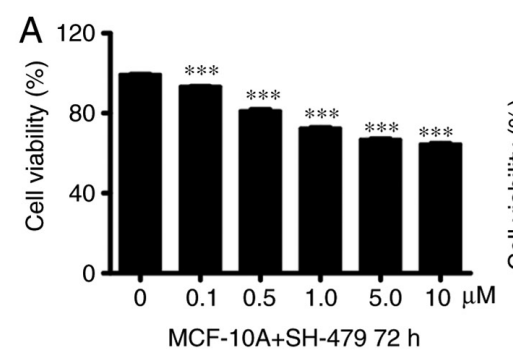

MCF-10A+SH-479 72 h
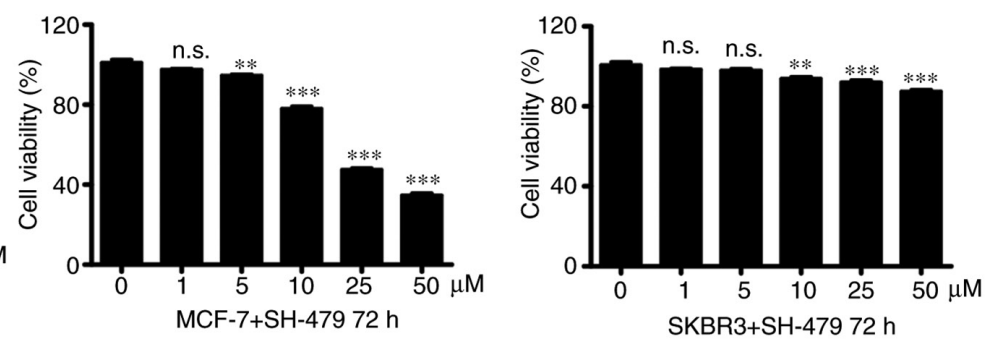

B MCF-10A+SH-479 $72 \mathrm{~h}$

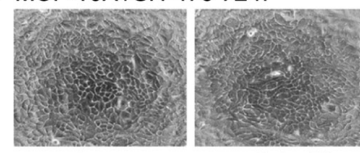

Control

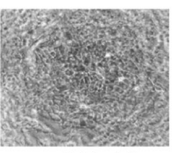

$0.5 \mu \mathrm{M}$

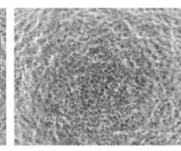

$1 \mu \mathrm{M}$

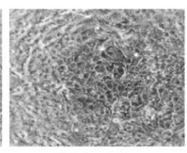

$2.5 \mu \mathrm{M}$

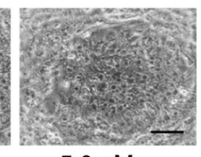

$5.0 \mu \mathrm{M}$

MDA-MB-231+SH-479 $72 \mathrm{~h}$

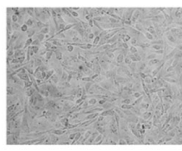

Control

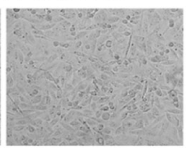

$0.1 \mu \mathrm{M}$

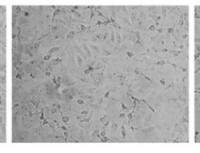

$0.5 \mu \mathrm{M}$

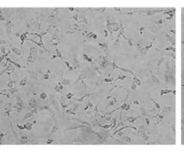

$1 \mu \mathrm{M}$

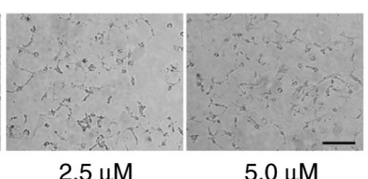

Figure 2. SH-479 inhibits the proliferation of MDA-MB-231cells. Normal breast cells MCF-10A and breast cancer cells were cultured with SH-479 for $72 \mathrm{~h}$ with indicated concentrations. (A) Effect of SH-479 on MCF-10A cell viability by MTS assay. Effect of SH-479 on MCF-7 and SKBR3 cell viability by MTS assay. (B) Morphology of MCF-10A and MDA-MB-231 was observed under microscope following treatment with SH-479 for $72 \mathrm{~h}$. Scale bar, $100 \mu \mathrm{m}$. Data were presented as the means \pm standard deviation of three individual experiments. ${ }^{* *} \mathrm{P}<0.01$ and ${ }^{* * * *} \mathrm{P}<0.001$.

normal breast tissue cells MCF-10 (Fig. 2B). However, when MDA-MB-231 cells were treated with SH-749, cells seemed to shrink and their morphology changed in a dose-dependent manner (Fig. 2B).

SH-479 alters microfilaments in breast cancer cells. The morphological changes of cell shrinkage might be caused by cell death or by structural changes within the cells. The results demonstrated that after $30 \mathrm{~h}$ treatment with SH-479 (0.1-10 $\mu \mathrm{M})$, MDA-MB-231 cells presented morphological shrinkage, although no cell death was observed. Green fluorescence represents living cells and red fluorescence represents dead cells (Fig. 3A). After $72 \mathrm{~h}$ treatment with SH-479 (0.1-10 $\mu \mathrm{M})$, the microfilaments of MDA-MB-231 cells were altered according to F-actin staining. The red fluorescence indicates the cytoskeleton and the blue 


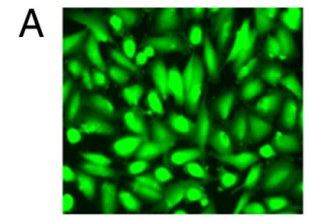

0

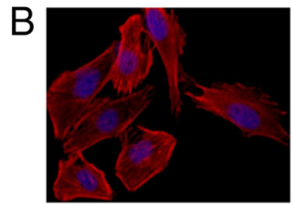

0

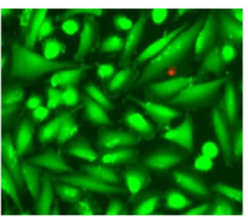

0.1

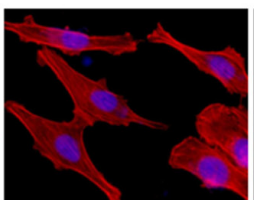

0.1

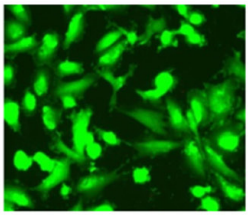

0.5

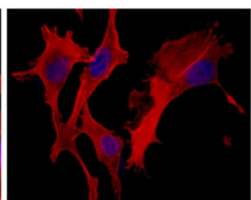

0.5

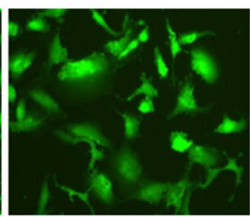

1.0

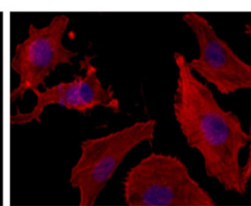

1.0

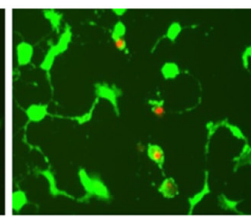

5.0

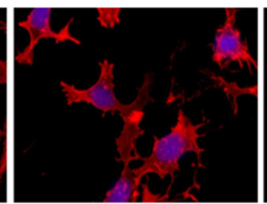

5.0

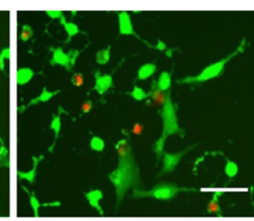

$10 \mu \mathrm{M}$

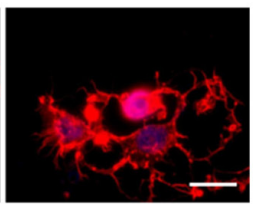

$10 \mu \mathrm{M}$
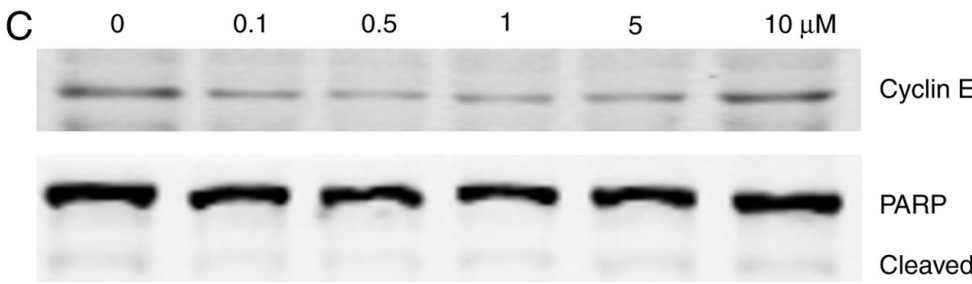

PARP

Cleaved PARP

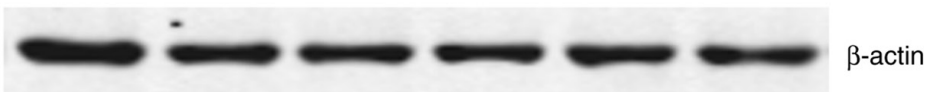

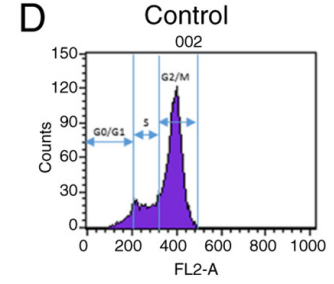

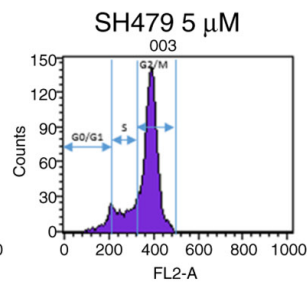

$\mathrm{Oh}$
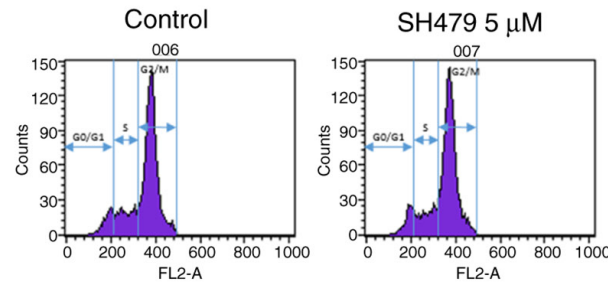

$12 \mathrm{~h}$

Figure 3. Inhibitory effect of SH-479 on breast cancer cells and effect on cytoskeleton. Breast cancer cells MDA-MB-231 were treated with SH-479 with indicated concentrations. (A) Cytotoxicity of SH-479 on breast cancer cells was detected using the Live and Dead assay. Scale bar, $100 \mu \mathrm{m}$. (B) Cytoskeleton of breast cancer cells was detected by F-actin staining. Scale bar, $50 \mu \mathrm{m}$. (C) Expression of proteins involved in cell cycle and apoptosis was detected by western blotting. (D) Cell cycle was detected by flow cytometry.

fluorescence indicates the nucleus (Fig. 3B). Because SH-479 can inhibit TNBC cell viability, cell cycle and apoptosis were determined. The expression of cyclin E starts in the middle phase of G1 phase and gradually decreases after reaching the peak in $\mathrm{G} 1 / \mathrm{S}$ phase. Cyclin $\mathrm{E}$ is therefore the key protein of $\mathrm{G} 1$ to $\mathrm{S}$ phase. The results demonstrated that $\mathrm{SH}-479$ had no effect on cell cycle transition from G1 phase to $S$ phase. There was no change in the expression of proteins involved in cell cycle and apoptosis in MDA-MB-231 cells treated with SH-479 (Fig. 3C). In order to further verify the effect of SH-479 on MDA-MB-231 cell cycle, cell cycle was determined by flow cytometry. The results demonstrated that after $12 \mathrm{~h}$ treatment with $5 \mu \mathrm{M} \mathrm{SH}-479$, the cell cycle of MDA-MB-231 cells was not modified (Fig. 3D).

SH-479 inhibits breast cancer cell migratory ability and breast cancer cell-induced osteoclast differentiation. The incidence of bone metastases in breast cancer is high, and TNBC usually leads to osteolytic bone metastasis. In the present study, MDA-MB-231 cell treatment with SH-479 induced a significant decrease in cell migratory ability in a dose-dependent manner (Fig. 4A). Furthermore, SH-479 treatment led to a decrease in the capacity of MDA-MB-231 cells to induce osteoclast differentiation in a dose-dependent manner (Fig. 4B).

Effects of SH-479 on bone marrow immune microenvironment. When bone metastasis occurs in patients with breast cancer, immune cells in the bone marrow microenvironment play an important role in the colonization and development of cancer cells. The results from the present study demonstrated that the number of CD3+CD4+T lymphocytes in the bone marrow microenvironment was significantly increased following treatment with SH-479 for $48 \mathrm{~h}$ (Fig. 5A). Furthermore, the number of MDSCs in the bone marrow microenvironment also serves a role in breast cancer metastasis to bones, and it can indirectly promote the development of breast cancer cells in the bone microenvironment by inhibiting the function of immune cells. The results from the present study demonstrated that SH-479 treatment decreased the number of MDSCs in bone microenvironment (Fig. 5B).

\section{Discussion}

TNBC is one subtype of breast cancer that lacks specific therapeutic targets. TNBC is characterized by a strong 
A MDA-MB-231+SH-479 migration assay

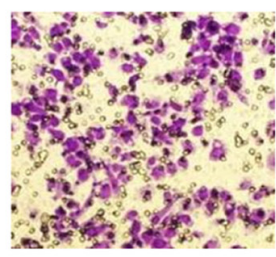

Control

B

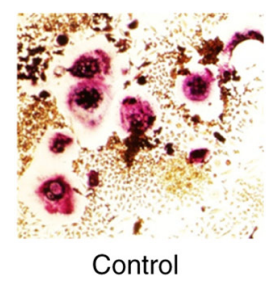

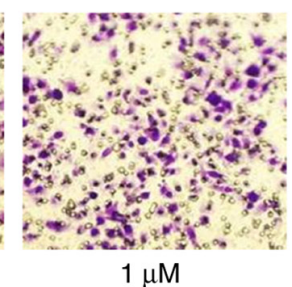

$1 \mu \mathrm{M}$

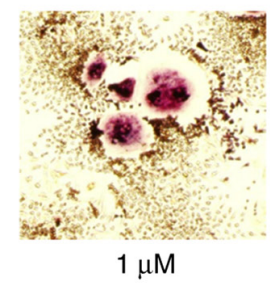

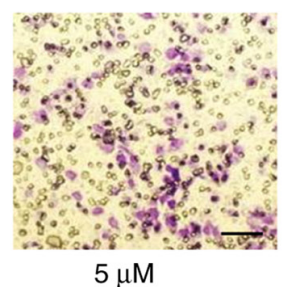

$5 \mu \mathrm{M}$

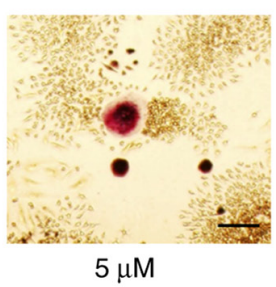

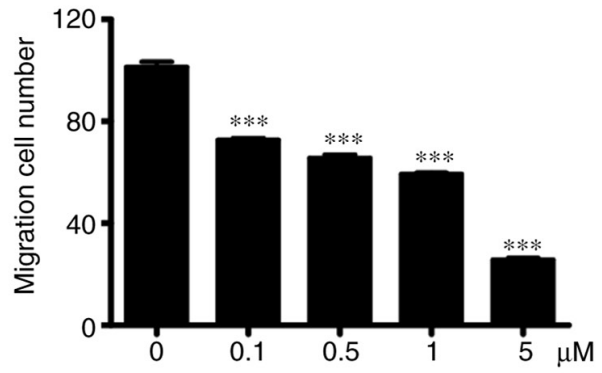

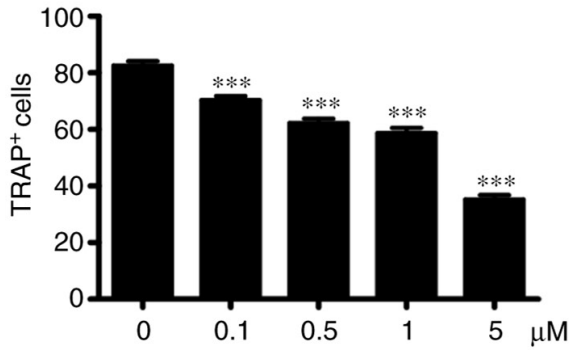

Figure 4. SH-479 inhibits osteoclast differentiation and breast cancer cell migratory ability. SH-479 was added to cells as the indicated concentrations (A) Migratory ability of MDA-MB-231 cells was measured using the migration assay. Scale bar, $100 \mu \mathrm{m}$. (B) Osteoclast differentiation was detected by TRAP staining. Scale bar, $50 \mu \mathrm{m}$. Data were presented as the means \pm standard deviation of three individual experiments. ${ }^{* * *} \mathrm{P}<0.001$. TRAP, tartrate-resistant acid phosphatase.

A

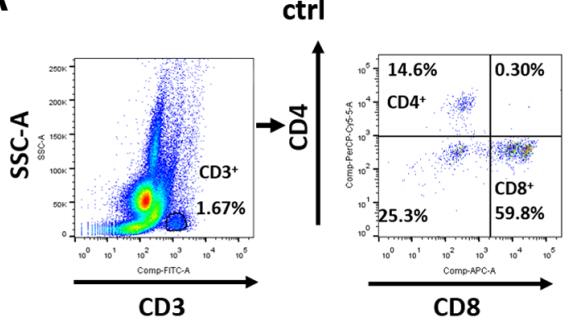

SH-479 $(10 \mu \mathrm{M})$
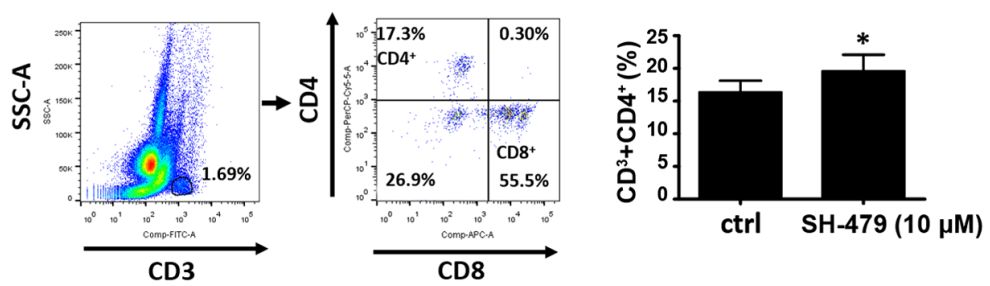

B

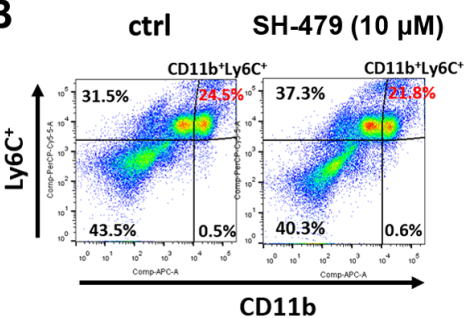

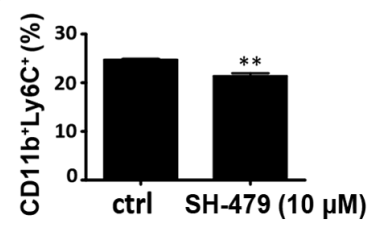

ctrl SH-479 (10 $\mu \mathrm{M})$

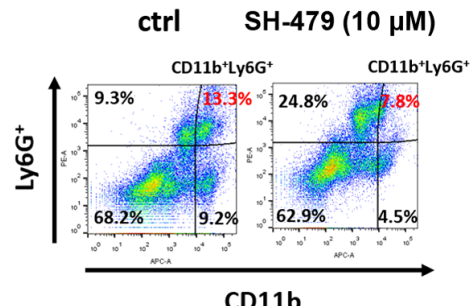

CD11b

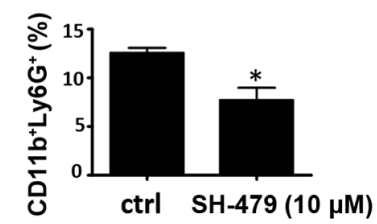

Figure 5. SH-479 can enhance the immune microenvironment of bone marrow. SH-479 was added to cells as the indicated concentrations. (A) Number of CD3+CD4+T lymphocytes was determined by flow cytometry. (B) Number of MDSCs (CD11b+) in bone marrow was determined by flow cytometry. Data were presented as the means \pm standard deviation of three individual experiments. ${ }^{*} \mathrm{P}<0.05$ and ${ }^{* *} \mathrm{P}<0.01$. Ctrl, control.

invasiveness and a poor prognosis. In the present study, SH-479 had small inhibitory effect on normal breast cell MCF-10A but had a significant inhibitory effect on the viability of MDA-MB-231 cells, which was not the case for the other types of breast cancer cells. SH-479 had no effect on the morphology of the normal breast tissue cells MCF-10, however, when MDA-MB-231 cells were treated with SH-749, cells seemed to shrink.

At present, conventional chemotherapy remains the main method of treatment for TNBC; however, drug resistance is likely to occur. Combined immunotherapy may be interesting for the treatment of TNBC (14). Immunotherapy provides good results on numerous types of cancer, including melanoma, lymphoma and prostate cancer (33). Due to the lack of therapeutic targets for TNBC, it is difficult for traditional treatments to achieve ideal therapeutic effect. Previous studies have reported that PD-L1 is highly expressed in TNBC and that it is associated with increased T lymphocyte infiltration (34-36). Regarding tumor treatment with immunotherapy, a class of MDSCs with immunosuppressive effect deserves some attention. MDSCs in the tumor microenvironment can reduce the innate immunity and adaptive immunity by inhibiting the proliferation of $\mathrm{T}$ lymphocyte and NK cells $(37,38)$. 
The present study demonstrated that SH-479 could reduce the proportion of MDSC in the bone marrow, which may stimulate the immune system to inhibit tumor growth. However, the therapeutic effect of SH-479 on breast cancer bone metastasis requires further in vivo investigation.

The role of BA in cancer is mainly due to the induction of cell apoptosis and changes in cell cycle $(39,40)$. In the present study, the apoptotic proteins PARP and cleaved PARP were detected by western blotting. No significant effect of SH-479 on PARP and cleaved PARP expression was observed. In addition, no significant cell death was observed in MDA-MB-231 cells following treatment with SH-479. The results from flow cytometry demonstrated that SH-479 had no significant effect on cell cycle. Microfilaments play an important role in tumor cell migration and are involved in cell migratory ability, suggesting that they may serve a crucial role in the occurrence of cancer metastasis $(39,41)$. In the present study, SH-479 treatment altered the microfilament structure of MDA-MB-231 cells and inhibited the migratory ability of MDA-MB-231 cells, suggesting that impaired migratory ability may be related to microfilament interference in these cells. Cell microfilaments play an important role in cell proliferation and form contraction rings with myosin during mitosis (42-44). Following treatment with SH-479, MDA-MB-231 cell proliferation was inhibited, which may be related to cell microfilament interference. Because $\mathrm{SH}-479$ is the ligand of the $\mathrm{G}$ protein-coupled bile acid receptor 1, it plays a regulatory role through $\mathrm{G}$-protein-coupled receptors (GPCRs) (31). Previous studies have reported that GPCR can regulate F-actin by regulating Hippo signaling pathway and YAP/TAZ activity. The Hippo pathway is highly conserved in mammals. MST1/2 (Hpo orthologs), Sav1, Lats1/2 (Wts orthologs) and Mob1 (MOBKL1A and MOBKL1B, Mats orthologs) form a kinase cascade that phosphorylates and inhibits YAP/TAZ (Yki orthologs). YAP/TAZ in conjunction with TEAD1-4 (Sd orthologs) mediate major physiological functions of the Hippo pathway (45-49). The hippo signaling pathway can be used as a theoretical basis for further research. The activation of osteoclasts plays an important role in the process of breast cancer metastasis to bone. Tumor cells can activate osteoclasts directly or indirectly by secreting cytokines. The growth factors released by osteoclasts after absorbing bone tissue can promote the proliferation of tumor cells and therefore lead to a vicious circle (50). We previously demonstrated that $\mathrm{SH}-479$ could directly inhibit osteoclast differentiation (23). The present study showed that SH-479 had the ability to inhibit osteoclast differentiation induced by tumor cells, suggesting that it may therefore have potential therapeutic effects on breast cancer metastasis of the bone.

In conclusion, the present study demonstrated that $\mathrm{SH}-479$ inhibited the activity of TNBC cells, the migratory ability of TNBC cells and the differentiation of osteoclasts induced by TNBCs. It was also demonstrated to enhance the immune microenvironment of bone marrow. These findings indicate that SH-479 may have a potential therapeutic significance for breast cancer metastasis of the bone.

\section{Acknowledgements}

Not applicable.

\section{Funding}

This study was funded by the Science and Technology Commission of Shanghai Municipality (grant no. 17411950301) and the Science and Technology Commission of Shanghai Municipality (grant no. 17ZR1439000).

\section{Availability of data and materials}

The datasets used and/or analyzed during the current study are available from the corresponding author on reasonable request.

\section{Authors' contributions}

JX, JZ, ZL and HW designed the study and HW approved the final version to be submitted. LT, SL, TH, WG and YX performed experiments, acquired data and drafted the manuscript. ZW, MQ, XG, XL and TW analyzed and interpretated the data. YX, XG, TW, TH, XL, XG and WG revised the manuscript for intellectual content. All authors read and approved the final manuscript. LT and HW confirmed the authenticity of all the raw data.

\section{Ethics approval and consent to participate}

The study was approved by the Animal Experiment Ethics Committee of East China Normal University (approval no. $\mathrm{m} 20151002)$.

\section{Patient consent for publication}

Not applicable.

\section{Competing interests}

The authors declare that they have no competing interests.

\section{References}

1. Beiki O, Hall P, Ekbom A and Moradi T: Breast cancer incidence and case fatality among 4.7 million women in relation to social and ethnic background: A population-based cohort study. Breast Cancer Res 14: R5, 2012.

2. Perou CM, Sørlie T, Eisen MB, van de Rijn M, Jeffrey SS, Rees CA, Pollack JR, Ross DT, Johnsen H, Akslen LA, et al: Molecular portraits of human breast tumours. Nature 406: 747-752, 2000

3. Buijs JT and van der Pluijm G: Osteotropic cancers: From primary tumor to bone. Cancer Lett 273: 177-193, 2009.

4. Coleman RE: Metastatic bone disease: Clinical features, pathophysiology and treatment strategies. Cancer Treat Rev 27: 165-176, 2001.

5. Fang J and Xu Q: Differences of osteoblastic bone metastases and osteolytic bone metastases in clinical features and molecular characteristics. Clin Transl Oncol 17: 173-179, 2015.

6. Kuchuk I, Hutton B, Moretto P, Ng T, Addison CL and Clemons $\mathrm{M}$ : Incidence, consequences and treatment of bone metastases in breast cancer patients-Experience from a single cancer centre. J Bone Oncol 2: 137-144, 2013.

7. Harries M, Taylor A, Holmberg L, Agbaje O, Garmo H, Kabilan S and Purushotham A: Incidence of bone metastases and survival after a diagnosis of bone metastases in breast cancer patients. Cancer Epidemiol 38: 427-434, 2014.

8. Brenton JD, Carey LA, Ahmed AA and Caldas C: Molecular classification and molecular forecasting of breast cancer: Ready for clinical application? J Clin Oncol 23: 7350-7360, 2005.

9. Carey LA, Dees EC, Sawyer L, Gatti L, Moore DT, Collichio F, Ollila DW, Sartor CI, Graham ML and Perou CM: The triple negative paradox: Primary tumor chemosensitivity of breast cancer subtypes. Clin Cancer Res 13: 2329-2334, 2007. 
10. Oakman C, Viale G and Di Leo A: Management of triple negative breast cancer. Breast 19: 312-321, 2010.

11. Morris GJ, Naidu S, Topham AK, Guiles F, Xu Y, McCue P, Schwartz GF, Park PK, Rosenberg AL, Brill K, et al: Differences in breast carcinoma characteristics in newly diagnosed African-American and Caucasian patients: A single-institution compilation compared with the National Cancer Institute's Surveillance, Epidemiology, and End Results database. Cancer 110: 876-884, 2007.

12. Rakha EA, El-Sayed ME, Green AR, Lee AH, Robertson JF and Ellis IO: Prognostic markers in triple-negative breast cancer. Cancer 109: 25-32, 2007.

13. Liedtke C, Mazouni C, Hess KR, André F, Tordai A, Mejia JA, Symmans WF, Gonzalez-Angulo AM, Hennessy B, Green M, et al: Response to neoadjuvant therapy and long-term survival in patients with triple-negative breast cancer. J Clin Oncol 26: 1275-1281, 2008

14. Katz $\mathrm{H}$ and Alsharedi $\mathrm{M}$ : Immunotherapy in triple-negative breast cancer. Med Oncol 35: 13, 2017.

15. Ji HF, Li XJ and Zhang HY: Natural products and drug discovery. Can thousands of years of ancient medical knowledge lead us to new and powerful drug combinations in the fight against cancer and dementia? EMBO Rep 10: 194-200, 2009.

16. Chowdhury AR, Mandal S, Mittra B, Sharma S, Mukhopadhyay S and Majumder HK: Betulinic acid, a potent inhibitor of eukaryotic topoisomerase I: Identification of the inhibitory step, the major functional group responsible and development of more potent derivatives. Med Sci Monit 8: BR254-BR265, 2002.

17. Viji V, Helen A and Luxmi VR: Betulinic acid inhibits endotoxin-stimulated phosphorylation cascade and pro-inflammatory prostaglandin $\mathrm{E}(2)$ production in human peripheral blood mononuclear cells. Br J Pharmacol 162: 1291-1303, 2011.

18. de Melo CL, Queiroz MG, Arruda Filho AC, Rodrigues AM, de Sousa DF, Almeida JG, Pessoa OD, Silveira ER, Menezes DB, Melo TS, et al: Betulinic acid, a natural pentacyclic triterpenoid, prevents abdominal fat accumulation in mice fed a high-fat diet. J Agric Food Chem 57: 8776-8781, 2009.

19. Genet C, Strehle A, Schmidt C, Boudjelal G, Lobstein A, Schoonjans K, Souchet M, Auwerx J, Saladin R and Wagner A: Structure-activity relationship study of betulinic acid, a novel and selective TGR5 agonist, and its synthetic derivatives: Potential impact in diabetes. J Med Chem 53: 178-190, 2010.

20. de Sá MS, Costa JF, Krettli AU, Zalis MG, Maia GL, Sette IM, Câmara CA, Filho JM, Giulietti-Harley AM, Ribeiro Dos Santos R, et al: Antimalarial activity of betulinic acid and derivatives in vitro against Plasmodium falciparum and in vivo in P. berghei-infected mice. Parasitol Res 105: 275-279, 2009.

21. Aisha AF, Ismail Z, Abu-Salah KM, Siddiqui JM, Ghafar G and Abdul Majid AM: Syzygium campanulatum korth methanolic extract inhibits angiogenesis and tumor growth in nude mice. BMC Complement Altern Med 13: 168, 2013.

22. Fulda S: Betulinic acid: A natural product with anticancer activity. Mol Nutr Food Res 53: 140-146, 2009.

23. Xu J, Li Z, Luo J, Yang F, Liu T, Liu M, Qiu WW and Tang J: Synthesis and biological evaluation of heterocyclic ring-fused betulinic acid derivatives as novel inhibitors of osteoclast differentiation and bone resorption. J Med Chem 55: 3122-3134, 2012.

24. Liotta LA and Kohn EC: The microenvironment of the tumour-host interface. Nature 411: 375-379, 2001.

25. Nguyen DX, Bos PD and Massagué J: Metastasis: From dissemination to organ-specific colonization. Nat Rev Cancer 9: 274-284, 2009

26. Sawant A, Hensel JA, Chanda D, Harris BA, Siegal GP, Maheshwari A and Ponnazhagan S: Depletion of plasmacytoid dendritic cells inhibits tumor growth and prevents bone metastasis of breast cancer cells. J Immunol 189: 4258-4265, 2012

27. Tan W, Zhang W, Strasner A, Grivennikov S, Cheng JQ, Hoffman RM and Karin M: Tumour-infiltrating regulatory T cells stimulate mammary cancer metastasis through RANKL-RANK signalling. Nature 470: 548-553, 2011.

28. Sawant A and Ponnazhagan S: Myeloid-derived suppressor cells as osteoclast progenitors: A novel target for controlling osteolytic bone metastasis. Cancer Res 73: 4606-4610, 2013.

29. Sung B, Pandey MK, Ahn KS, Yi T, Chaturvedi MM, Liu M and Aggarwal BB: Anacardic acid (6-nonadecyl salicylic acid), an inhibitor of histone acetyltransferase, suppresses expression of nuclear factor-kappaB-regulated gene products involved in cell survival, proliferation, invasion, and inflammation through inhibition of the inhibitory subunit of nuclear factor-kappaBalpha kinase, leading to potentiation of apoptosis. Blood 111: 4880-4891, 2008 .
30. Hou T, Lou Y, Li S, Zhao C, Ji Y, Wang D, Tang L, Zhou M, $\mathrm{Xu}$ W, Qian M, et al: Kadsurenone is a useful and promising treatment strategy for breast cancer bone metastases by blocking the PAF/PTAFR signaling pathway. Oncol Lett 16: 2255-2262, 2018.

31. Li Z, Huang J, Wang F, Li W, Wu X, Zhao C, Zhao J, Wei H, Wu Z Qian M, et al: Dual targeting of Bile Acid Receptor-1 (TGR5) and Farnesoid X Receptor (FXR) prevents estrogen-dependent bone loss in mice. J Bone Miner Res 34: 765-776, 2019.

32. van der Heide V, Möhnle P, Rink J, Briegel J and Kreth S: Down-regulation of MicroRNA-31 in CD4+ T cells contributes to immunosuppression in human sepsis by promoting $\mathrm{TH} 2$ skewing. Anesthesiology 124: 908-922, 2016.

33. Topalian SL, Drake CG and Pardoll DM: Immune checkpoint blockade: A common denominator approach to cancer therapy. Cancer Cell 27: 450-461, 2015.

34. Pusztai L, Karn T, Safonov A, Abu-Khalaf MM and Bianchini G: New strategies in breast cancer: Immunotherapy. Clin Cancer Res 22: 2105-2110, 2016.

35. McArthur HL and Page DB: Immunotherapy for the treatment of breast cancer: Checkpoint blockade, cancer vaccines, and future directions in combination immunotherapy. Clin Adv Hematol Oncol 14: 922-933, 2016.

36. Schalper KA, Velcheti V, Carvajal D, Wimberly H, Brown J, Pusztai L and Rimm DL: In situ tumor PD-L1 mRNA expression is associated with increased TILs and better outcome in breast carcinomas. Clin Cancer Res 20: 2773-2782, 2014.

37. Sinha P, Clements VK and Ostrand-Rosenberg S: Reduction of myeloid-derived suppressor cells and induction of M1 macrophages facilitate the rejection of established metastatic disease. J Immunol 174: 636-645, 2005.

38. Suzuki E, Kapoor V, Jassar AS, Kaiser LR and Albelda SM: Gemcitabine selectively eliminates splenic Gr-1+/CD11b+ myeloid suppressor cells in tumor-bearing animals and enhances antitumor immune activity. Clin Cancer Res 11: 6713-6721, 2005.

39. Friedl P and Alexander S: Cancer invasion and the microenvironment: Plasticity and reciprocity. Cell 147: 992-1009, 2011.

40. Mullauer FB, Kessler JH and Medema JP: Betulinic acid, a natural compound with potent anticancer effects. Anticancer Drugs 21: 215-227, 2010.

41. Petrie RJ and Yamada KM: At the leading edge of three-dimensional cell migration. J Cell Sci 125: 5917-5926, 2012.

42. Akhshi TK, Wernike D and Piekny A: Microtubules and actin crosstalk in cell migration and division. Cytoskeleton (Hoboken) 71: 1-23, 2014.

43. Goode BL and Eck MJ: Mechanism and function of formins in the control of actin assembly. Annu Rev Biochem 76: 593-627, 2007.

44. Kovar DR: Molecular details of formin-mediated actin assembly. Curr Opin Cell Biol 18: 11-17, 2006.

45. Aragona M, Panciera T, Manfrin A, Giulitti S, Michielin F, Elvassore N, Dupont S and Piccolo S: A mechanical checkpoint controls multicellular growth through YAP/TAZ regulation by actin-processing factors. Cell 154: 1047-1059, 2013.

46. Yu FX and Guan KL: The Hippo pathway: Regulators and regulations. Genes Dev 27: 355-371, 2013.

47. Zhang Y, Xiao Y, Dong Q, Ouyang W and Qin Q: Neferine in the Lotus Plumule Potentiates the Antitumor Effect of Imatinib in Primary Chronic Myeloid Leukemia Cells In Vitro. J Food Sci 84: 904-910, 2019.

48. Pan D: The hippo signaling pathway in development and cancer. Dev Cell 19: 491-505, 2010.

49. Zhao B, Li L, Lei Q and Guan KL: The Hippo-YAP pathway in organ size control and tumorigenesis: An updated version. Genes Dev 24: 862-874, 2010.

50. Yoneda T, Michigami T, Yi B, Williams PJ, Niewolna M and Hiraga T: Use of bisphosphonates for the treatment of bone metastasis in experimental animal models. Cancer Treat Rev 25: 293-299, 1999.

This work is licensed under a Creative Commons Attribution-NonCommercial-NoDerivatives 4.0 International (CC BY-NC-ND 4.0) License. 